\title{
Salusin- $\beta$ contributes to oxidative stress and inflammation in diabetic cardiomyopathy
}

\author{
Ming-Xia Zhao ${ }^{1}$, Bing Zhou ${ }^{1}$, Li Ling ${ }^{1}$, Xiao-Qing Xiong ${ }^{1}$, Feng Zhang ${ }^{1}$, Qi Chen ${ }^{2}$, Yue-Hua Liं ${ }^{2}$, Yu-Ming Kang ${ }^{3}$ and Guo-Qing Zhu*,1,2
}

Salusin- $\beta$ accelerates inflammatory responses in vascular endothelial cells, and increases oxidative stress in vascular smooth muscle cells. Plasma salusin- $\beta$ levels were increased in diabetic patients. This study was designed to determine whether salusin- $\beta$ is involved in the pathogenesis of diabetic cardiomyopathy (DCM), and whether knockdown of salusin- $\beta$ attenuates cardiac inflammation and oxidative stress in rats with DCM. H9c2 or neonatal rat cardiomyocytes were incubated with $33.3 \mathrm{mM}$ of glucose to mimic the high glucose (HG) in diabetes. Streptozotocin and high-fat diet were used to induce type 2 diabetes in rats. HG induced salusin- $\beta$ expression in H9c2 cells. Salusin- $\beta$ caused greater responses of oxidative stress, NF $\kappa$ B activation and inflammation in HG-treated H9c2 cells than these in control H9c2 cells. Diphenyleneiodonium (a NAD(P)H oxidase inhibitor) or $N$-acetylcysteine (an antioxidant) inhibited the salusin- $\beta$-induced NF $\kappa$ B activation and inflammation. Bay11-7082 (a NF $\kappa$ B inhibitor) attenuated salusin- $\beta$-induced inflammation but not oxidative stress. Knockdown of salusin- $\beta$ prevented the HG-induced oxidative stress, NF $\kappa$ B activation and inflammation in neonatal rat cardiomyocytes. Silencing salusin- $\beta$ with adenoviruse-mediated shRNA had no significant effects on blood glucose and insulin resistance, but attenuated ventricular dysfunction in diabetic rats. Oxidative stress, NFKB activation, inflammation, salusin- $\beta$ upregulation in myocardium of diabetic rats were prevented by knockdown of salusin- $\beta$. These results indicate that salusin $\beta$ contributes to inflammation in DCM via NOX2/ROS/NF $\kappa B$ signaling, and that knockdown of salusin- $\beta$ attenuates cardiac dysfunction, oxidative stress and inflammation in DCM.

Cell Death and Disease (2017) 8, e2690; doi:10.1038/cddis.2017.106; published online 23 March 2017

Diabetic cardiomyopathy (DCM) comprises structural and functional abnormalities of the myocardium in diabetic patients or animals without hypertension or coronary artery disease. ${ }^{1,2}$ In diabetic heart, metabolic derangements, impairments in excitation-contraction coupling, loss of normal microvessels and remodeling of the extracellular matrix are involved in contractile dysfunction. ${ }^{3}$ It is known that diabetes or hyperglycemia increases intracellular reactive oxygen species (ROS), which subsequently induces injury and inflammation. ${ }^{4}$ Oxidative stress is closely associated with the pathogenesis of diabetes, and long-term exposure to oxidative stress in diabetes induces chronic inflammation. ${ }^{5}$ Oxidative stress may have a critical role in the development of DCM. ${ }^{6}$

Salusin- $\beta$ is identified as a bioactive peptide of hemodynamic and mitogenic activities. ${ }^{7}$ The initial 18 amino acids of human salusin- $\beta$ have high homology with the $N$-terminal sequence of rat salusin. ${ }^{8}$ Previous studies in our lab have shown that central salusin- $\beta$ contributes to sympathetic activation, arginine vasopressin release and hypertension. ${ }^{9-11}$ Salusin- $\beta$ promotes proliferation of vascular smooth muscle cells (VSMCs) and vascular fibrosis. ${ }^{12}$ ROS production in VSMCs mediates salusin- $\beta$-induced foam cell formation and monocyte adhesion, ${ }^{13}$ VSMCs migration and intimal hyperplasia after vascular injury. ${ }^{14}$ Knockdown of salusin- $\beta$ reduces ROS production in injured carotid arteries in rats. ${ }^{13}$ Salusin- $\beta$ has been implicated in inflammatory response in vascular endothelial cells. ${ }^{15,16}$ Patients with diabetes displayed a distinctly increase in plasma salusin- $\beta$ levels. ${ }^{17}$ Salusin- $\beta$ is widely distributed in a host of tissues, ${ }^{8}$ and can be synthesized locally in the muscle cells of the heart. ${ }^{18}$ It has been found that salusin- $\beta$ contributes to the development of coronary ligationinduced myocardial infarction in rats, and inhibition of endogenous salusin- $\beta$ may be useful to suppress ventricular remodeling after myocardial ischemia. ${ }^{19}$ We hypothesized that salusin- $\beta$ may have a critical role in DCM. In this study, we sought to explore the roles of salusin- $\beta$ in type $2 \mathrm{DCM}$ and the underlying molecular mechanism. This study was designed to determine whether salusin- $\beta$ was involved in the oxidative stress and inflammation of DCM. Furthermore, the effects of knockdown of salusin- $\beta$ on cardiac oxidative stress and inflammation were investigated in rats with DCM.

\section{Results}

Salusin- $\beta$ induces inflammation and oxidative stress in cardiomyocytes. Salusin- $\beta$ increased the levels of proinflammatory cytokines including interleukin- $1 \beta$ (IL-1 $\beta$ ), IL-6 and tumor necrosis factor- $a$ (TNF- $a$ ) in H9c2 cells. TNF- $a$ is known to aggravate heart inflammation via the upregulation of vascular cell adhesion molecule-1 (VCAM-1). ${ }^{20}$ 4-Hydroxynonenal (4-HNE) is a major marker of oxidative stress. ${ }^{21,22}$ Salusin- $\beta$ increased VCAM-1, NOX2 and 4-HNE expression levels, but had no significant effect on NOX4 expression in

\footnotetext{
${ }^{1}$ Department of Physiology, Key Laboratory of Cardiovascular Disease and Molecular Intervention, Nanjing Medical University, Nanjing, China; ${ }^{2}$ Department of Pathophysiology, Nanjing Medical University, Nanjing, China and ${ }^{3}$ Department of Physiology and Pathophysiology, Cardiovascular Research Center, Xi'an Jiaotong University School of Medicine, Xi'an, China

${ }^{*}$ Corresponding author: G-Q Zhu, Department of Physiology, Key Laboratory of Cardiovascular Disease and Molecular Intervention, Nanjing Medical University, 101 Longmian Avenue, Nanjing 210029, China. Tel/Fax: +86 25 86869351; E-mail: gqzhucn@njmu.edu.cn

Received 30.9.16; revised 10.2.17; accepted 15.2.17; Edited by A Finazzi-Agro'
} 

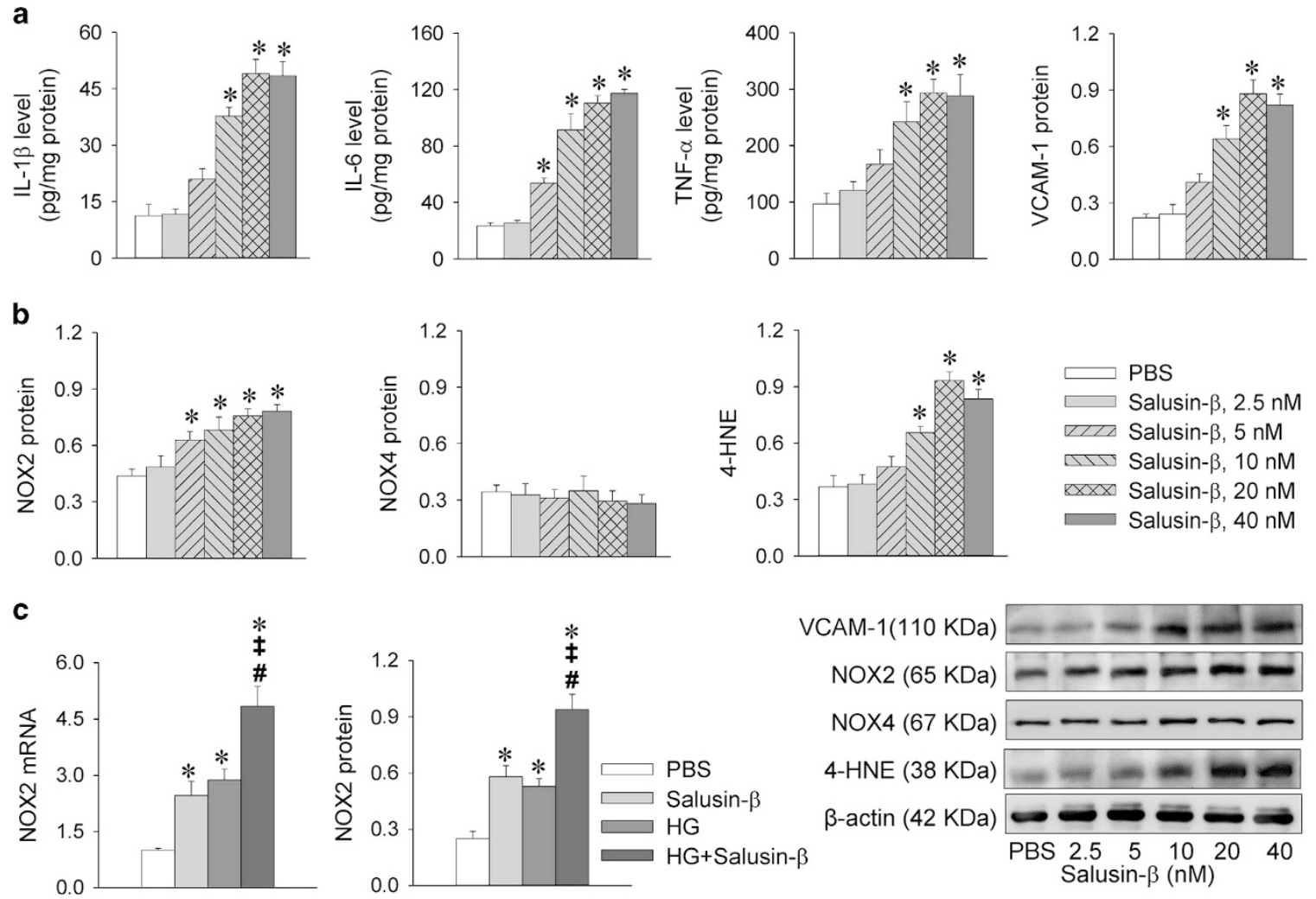

d
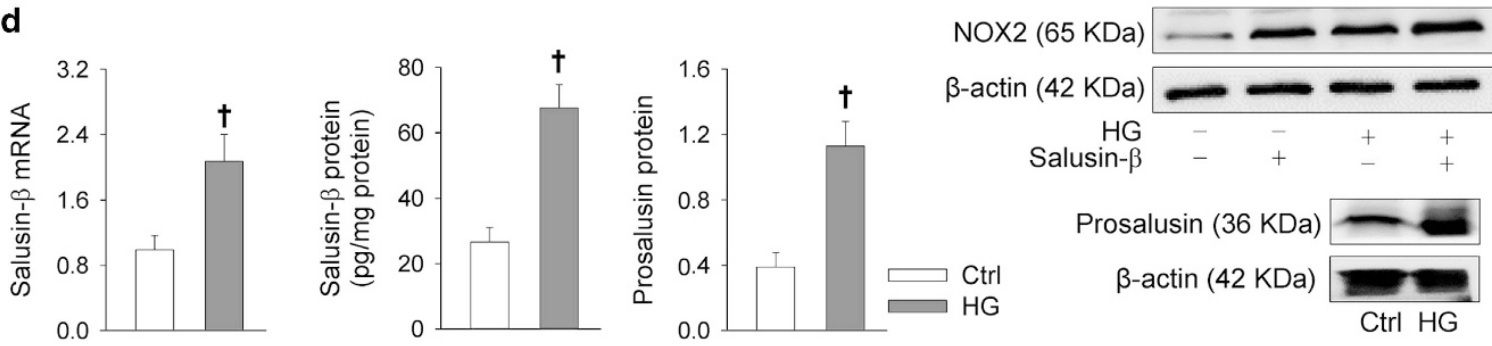

Figure 1 Effects of salusin- $\beta$ on inflammation and oxidative stress and effects of HG on salusin- $\beta$ and NOX2 expression levels in H9c2 cells. (a) Effects of salusin- $\beta$ on inflammation in H9c2 cells. (b) Effects of salusin- $\beta$ on oxidative stress in H9c2 cells. H9c2 cells were treated with different doses of salusin- $\beta(0,2.5,5,10,20$ or $40 \mathrm{nM})$ for $24 \mathrm{~h}$. ELISA was used to measure the levels of salusin- $\beta$, IL- $1 \beta$, IL-6 and TNF- $\alpha$. Western blotting was used to detect the relative levels VCAM-1, NOX2, NOX4 and 4-HNE. (c) Effects of salusin- $\beta(20 \mathrm{nM}$ for $24 \mathrm{~h}$ ) and HG (33.3 mM for $24 \mathrm{~h}$ ) on NOX2 mRNA and NOX2 expression levels. (d) Salusin- $\beta$ mRNA, salusin- $\beta$ protein and prosalusin levels in H9C2 cells treated with $\mathrm{HG}(33.3 \mathrm{mM})$ for $24 \mathrm{~h}$. Values are mean \pm S.E.M. ${ }^{*} P<0.05$ versus $\mathrm{PBS},{ }^{\dagger} P<0.05$ versus $\mathrm{Ctrl} .{ }^{\ddagger} P<0.05$ versus Salusin- $\beta$. ${ }^{\sharp} P<0.05$ versus HG. $n=6$

$\mathrm{H} 9 \mathrm{c} 2$ cells (Figures $1 \mathrm{a}$ and $\mathrm{b})$. These results indicate that salusin- $\beta$ causes inflammation and oxidative stress in $\mathrm{H} 9 \mathrm{c} 2$ cells. High glucose (HG) caused similar increases in NOX2 mRNA and protein expression levels in $\mathrm{H} 9 \mathrm{c} 2$ cells, and combined administration of $\mathrm{HG}$ and salusin- $\beta$ caused greater effects than salusin- $\beta$ or HG alone (Figure 1c). However, insulin had no significant effects on the salusin- $\beta$ and NOX2 expression levels in both baseline or HG state in $\mathrm{H} 9 \mathrm{c} 2$ cells (Supplementary Figure 1).

HG increases salusin- $\beta$ expression in cardiomyocytes. It is known that plasma salusin- $\beta$ levels are increased in diabetic patients. ${ }^{17}$ Treatment with $\mathrm{HG}$ for $24 \mathrm{~h}$ not only increased salusin- $\beta$ mRNA levels, but also upregulated salusin- $\beta$ and its precursor prosalusin protein expression levels in $\mathrm{H} 9 \mathrm{c} 2$ cells (Figure $1 \mathrm{~d}$ ), suggesting that $\mathrm{HG}$ is a stimulator of salusin- $\beta$ expression.

ROS contributes to HG- and salusin- $\beta$-induced inflammation and NFKB activation in cardiomyocytes. $H G$ is known to activate $\mathrm{NF}_{K} \mathrm{~B} .{ }^{23,24}$ In this study, $\mathrm{HG}$ caused inflammation evidenced by the upregulation of IL-1 $\beta$, IL-6, TNF- $a$ and VCAM-1, and NFKB activation indicated by the increased p65 in nucleus and reduced p65 in cytoplasm in $\mathrm{H} 9 \mathrm{c} 2$ cells. Salusin- $\beta$ induced greater responses in inflammation and $\mathrm{NF}_{K} \mathrm{~B}$ activation in $\mathrm{HG}$-treated $\mathrm{H} 9 \mathrm{c} 2$ cells than those in control cells. Inhibition of $\mathrm{NAD}(\mathrm{P}) \mathrm{H}$ oxidase (NOX) with diphenyleneiodonium (DPI) not only attenuated the $\mathrm{HG}$-induced inflammation and $\mathrm{NF} K \mathrm{~B}$ activation, but also salusin- $\beta$-induced inflammation and 

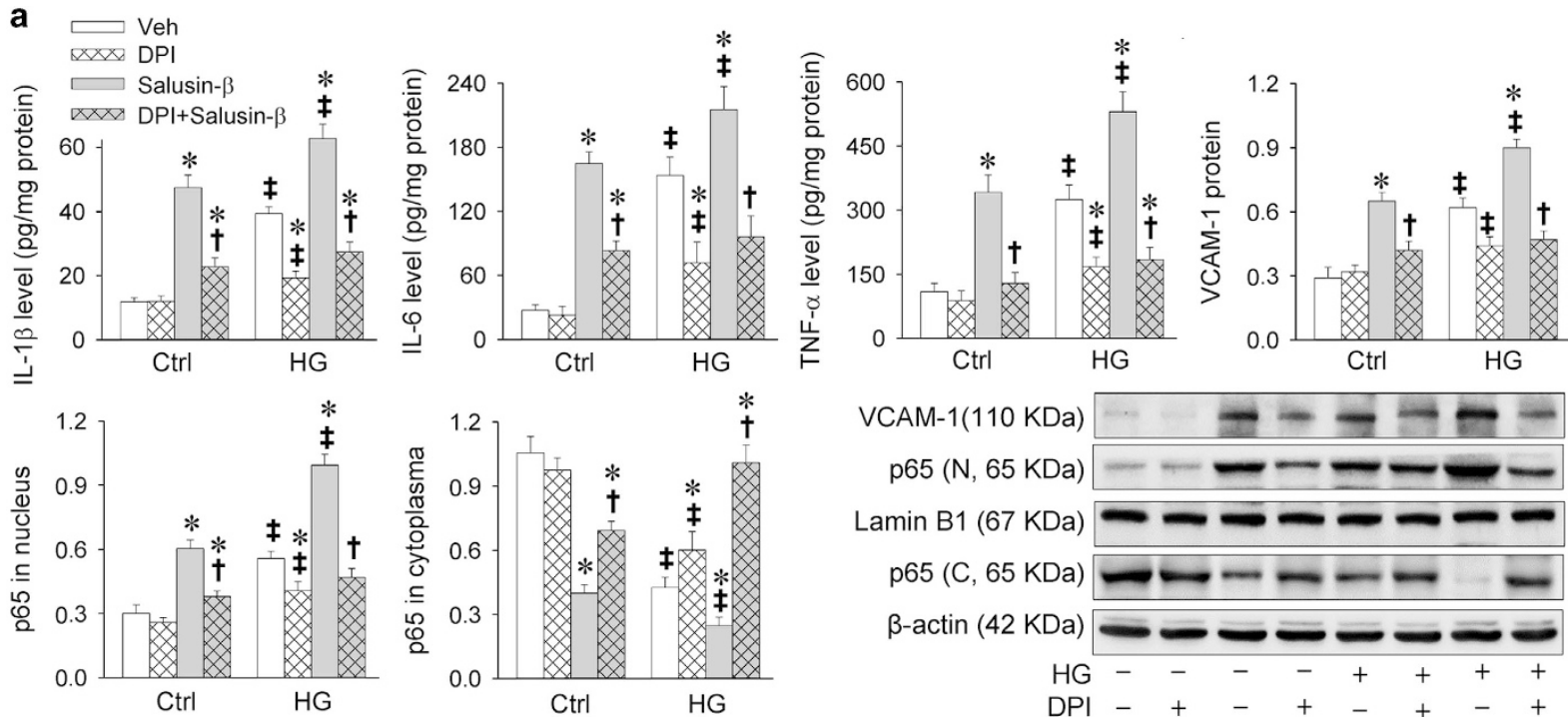

Lamin B1 (67 KDa) $=-m-m$

p65 (C, $65 \mathrm{KDa})$

$\beta$-actin (42 KDa)
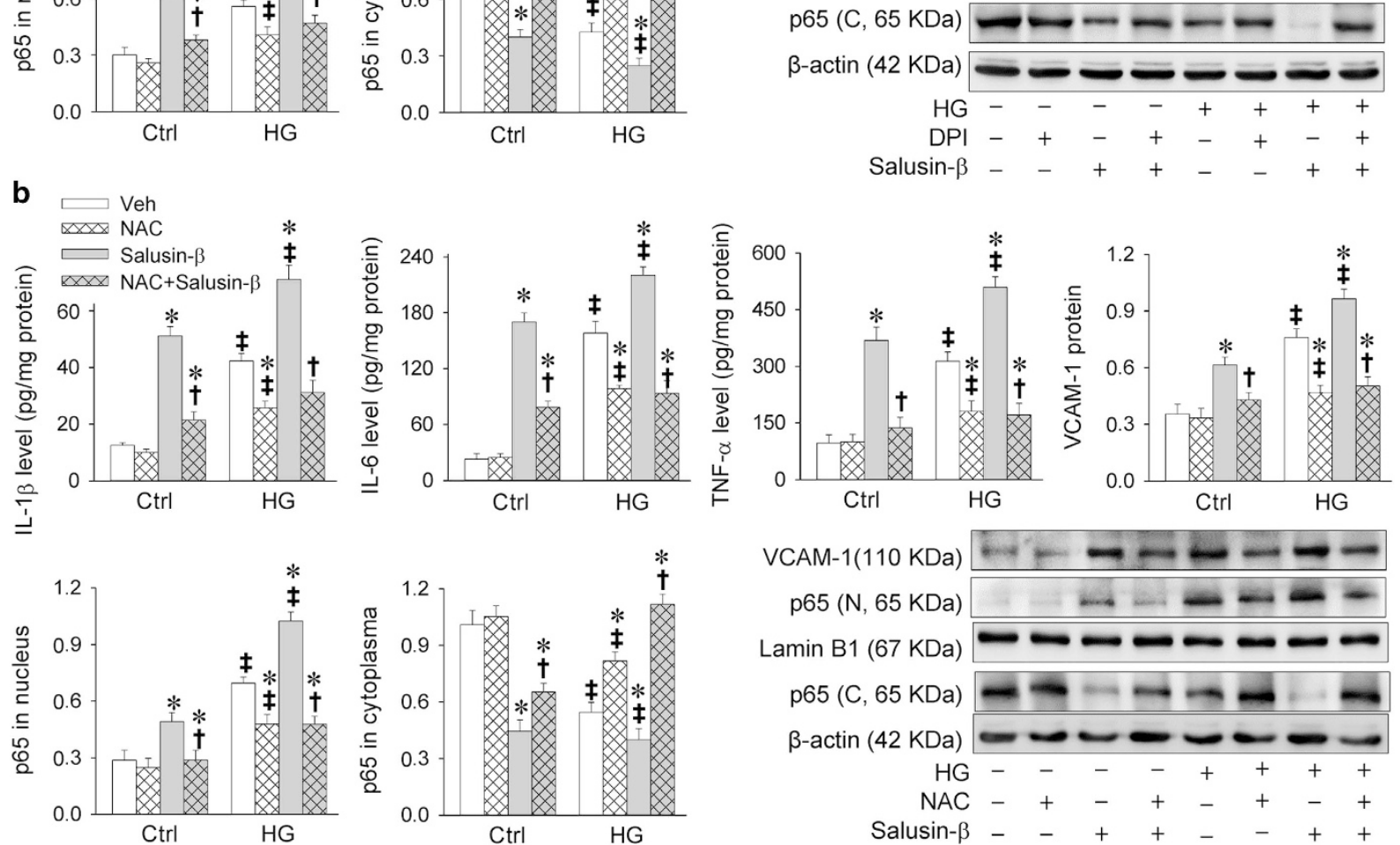

Figure 2 Effects of DPI (a NAD(P)H oxidase inhibitor) and NAC (an antioxidant) on salusin- $\beta$-induced inflammation and NF $k B$ activation in $\mathrm{H}_{\mathrm{c}} 2$ cells. $\mathrm{H} 9 \mathrm{c} 2 \mathrm{cells}$ were pretreated with DPI $(10 \mu \mathrm{M})$ or NAC (5 mM) for $1 \mathrm{~h}$ before incubated with salusin- $\beta(20 \mathrm{nM})$ or both salusin- $\beta(20 \mathrm{nM})$ and $\mathrm{HG}(33.3 \mathrm{mM})$ for $24 \mathrm{~h}$. (a) Effects of DPI on salusin- $\beta$ induced inflammation and $\mathrm{NF}_{\kappa} \mathrm{B}$ activation. (b) Effects of $\mathrm{NAC}$ on salusin- $\beta$-induced inflammation and $\mathrm{NF} \kappa \mathrm{B}$ activation. Values are mean $\pm \mathrm{S}$.E.M. ${ }^{*} P<0.05$ versus Veh; ${ }^{\dagger} P<0.05$ versus Salusin- $\beta .{ }^{\ddagger} P<0.05$ versus Ctrl. $n=6$

$\mathrm{NF} K \mathrm{~B}$ activation in both $\mathrm{HG}$-treated H9c2 cells and control cells (Figure 2a). Antioxidant $\mathrm{N}$-acetylcysteine (NAC) showed similar effects with DPI in attenuating HG- and salusin- $\beta$-induced inflammation and $\mathrm{NF} \kappa \mathrm{B}$ activation (Figure $2 b$ ).

Inhibition of NFKB attenuates HG- and salusin- $\beta$-induced inflammation in cardiomyocytes. Inhibition of $\mathrm{NF} \kappa \mathrm{B}$ with Bay 11-7082 attenuated salusin- $\beta$ - or HG-induced inflammation in $\mathrm{H} 9 \mathrm{c} 2$ cells (Figure 3a). However, Bay11-7082 had no significant effects on HG- or salusin- $\beta$-induced NOX2 and 4-HNE expression levels (Figure $3 b$ ).
Knockdown of salusin- $\beta$ attenuates HG-induced inflammation and oxidative stress in cardiomyocytes. Knockdown of salusin- $\beta$ with Ad-Salusin-shRNA dose- and timerelatedly reduced salusin- $\beta, \mathrm{IL}-1 \beta$, IL- 6 and TNF- $\alpha$ mRNA levels, and NOX2 protein and 4-HNE levels in HG-treated H9c2 cells, reaching its maximal effects at the multiplicity of infection $(\mathrm{MOI})=100$ (Supplementary Figure 2) treated for $24 \mathrm{~h}$ (Supplementary Figure 3). To confirm these findings, we further examined the effects of salusin- $\beta$-shRNA in neonatal rat cardiomyocytes. We found that salusin- $\beta$-shRNA attenuated HG-induced inflammation, NOX2 expression, ROS production and $\mathrm{NF} K \mathrm{~B}$ activation in $\mathrm{HG}$-treated neonatal rat cardiomyocytes, but had no significant effects in control cells (Figures $4 a-c)$. 

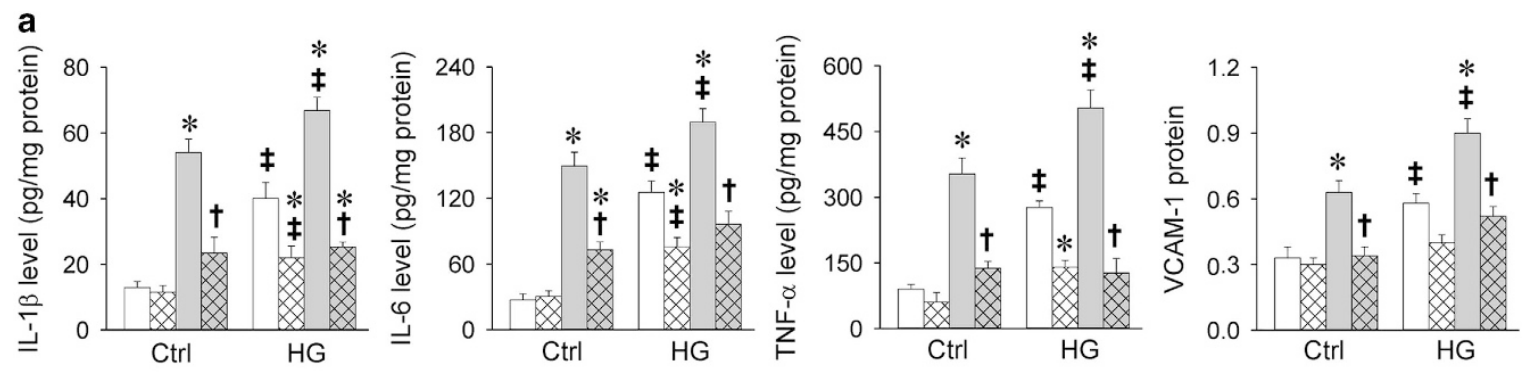

$\square$ Veh
\[ \times \times \text { Bay11-7082 } \]
$\square$ Salusin- $\beta$
$\bowtie \times \times$ Bay11-7082+Salusin- $\beta$
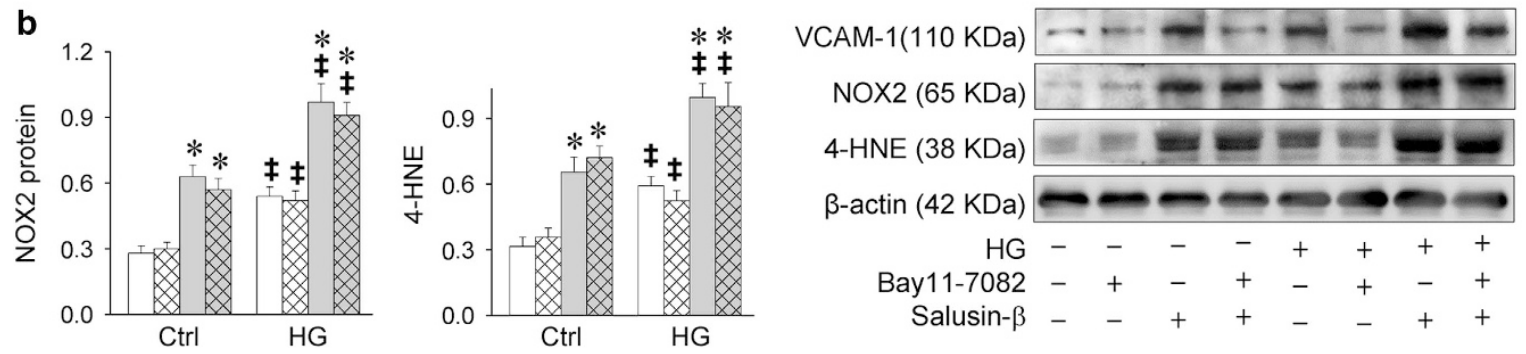

Figure 3 Effects of Bay11-7082 (a NFKB inhibitor) on salusin- $\beta$-induced inflammation and oxidative stress in H9c2 cells. H9c2 cells were pretreated with Bay11-7082 (10 $\mu \mathrm{M}$ ) for $1 \mathrm{~h}$ before incubated with salusin- $\beta(20 \mathrm{nM})$ or both salusin- $\beta(20 \mathrm{nM})$ and $\mathrm{HG}(33.3 \mathrm{mM})$ for $24 \mathrm{~h}$. (a) Effects of Bay 11-7082 on salusin- $\beta$-induced inflammation. (b) Effects of Bay11-7082 on salusin- $\beta$-induced oxidative stress. Values are mean \pm S.E.M. ${ }^{*} P<0.05$ versus Veh; ${ }^{\dagger} P<0.05$ versus Salusin- $\beta$. ${ }^{\ddagger} P<0.05$ versus Ctrl. $n=6$
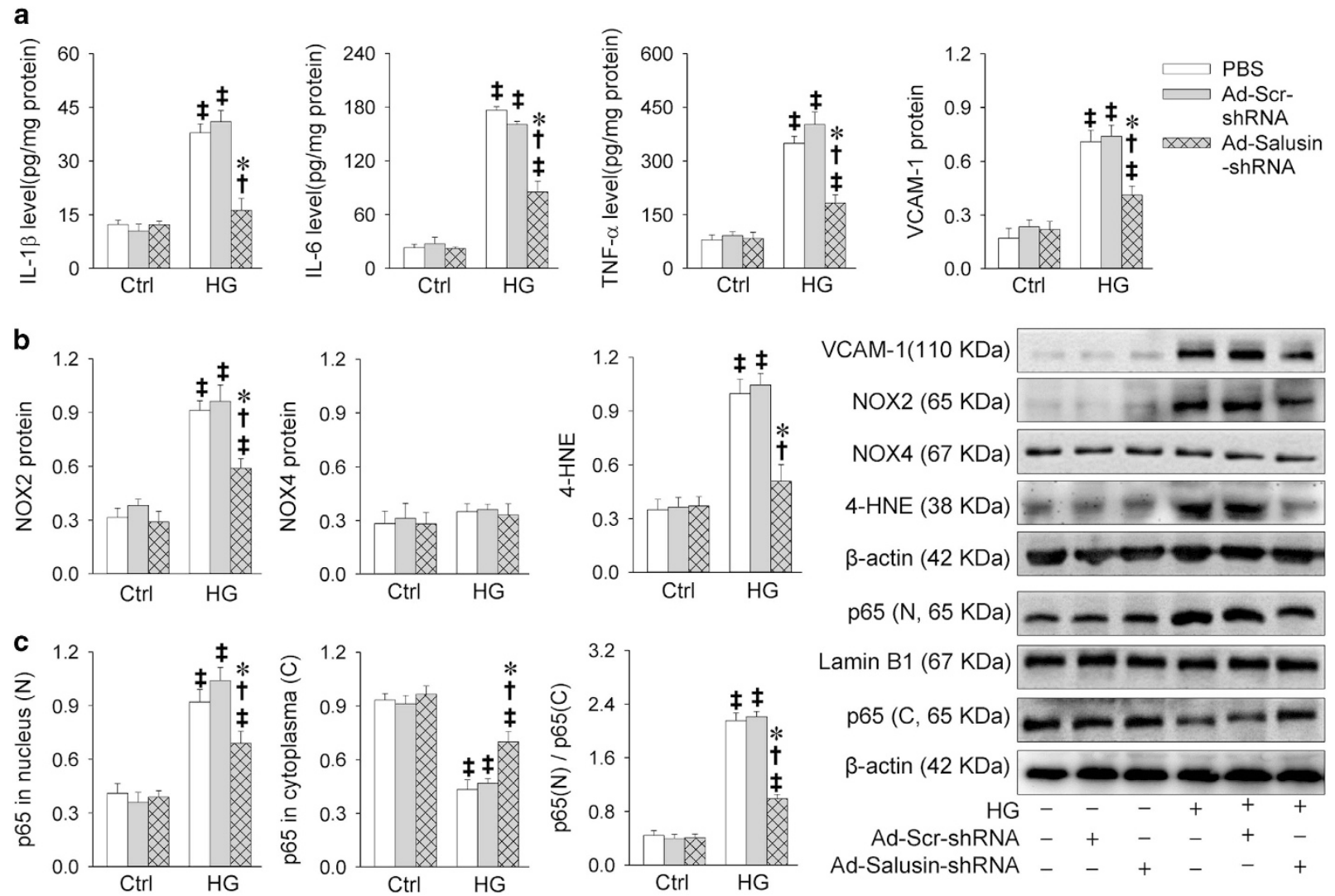

Lamin B1 $(67 \mathrm{KDa})=0$

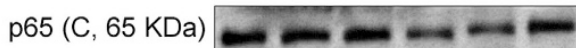

$\beta$-actin $(42 \mathrm{KDa})$

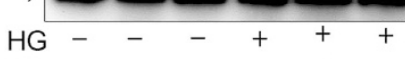

Ad-Scr-shRNA - + - -+

Figure 4 Effects of knockdown of salusin- $\beta$ with adenoviral vectors encoding salusin- $\beta$ shRNA (Ad-Salusin-shRNA) on inflammation, oxidative stress and NF $\kappa$ B activation in neonatal rat cardiomyocytes. The cardiomyocytes were treated with both Ad-Salusin-shRNA (MOI = 100) and HG (33.3 mM) for $24 \mathrm{~h}$. Adenoviral vectors encoding scramble shRNA (Ad-Scr-shRNA) was used as a control of Ad-salusin-shRNA. (a) Effects of Ad-Salusin-shRNA on inflammation. (b) Effects of Ad-Salusin-shRNA on oxidative stress. (c) Effects of Ad-Salusin-shRNA on NF $\kappa$ B activation. Values are mean \pm S.E.M. ${ }^{*} P<0.05$ versus $\mathrm{PBS}$; ${ }^{\dagger} P<0.05$ versus Ad-Scr-shRNA. ${ }^{\ddagger} P<0.05$ versus Ctrl. $n=6$ 
a
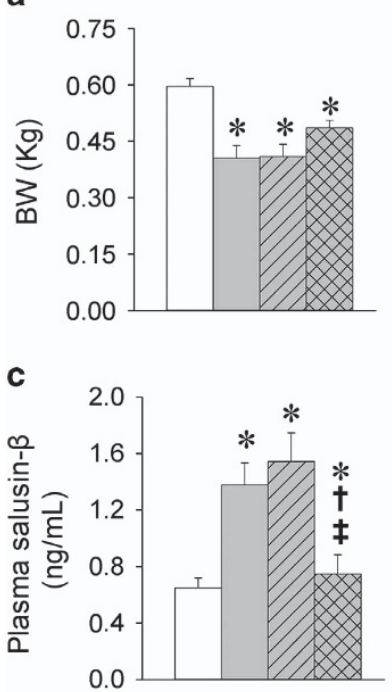

e
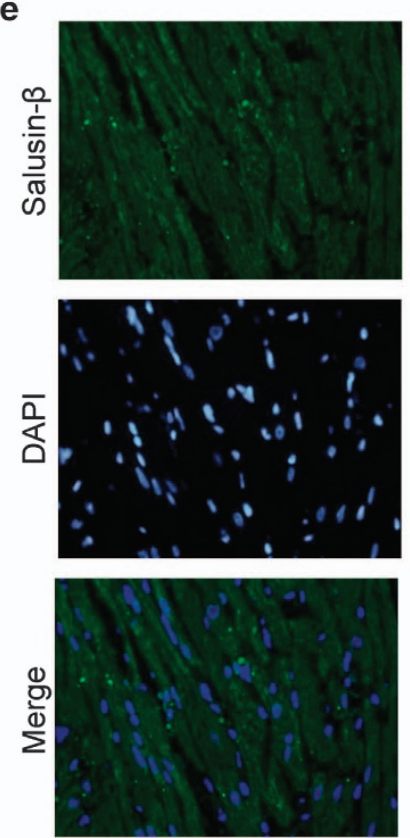

Ctrl
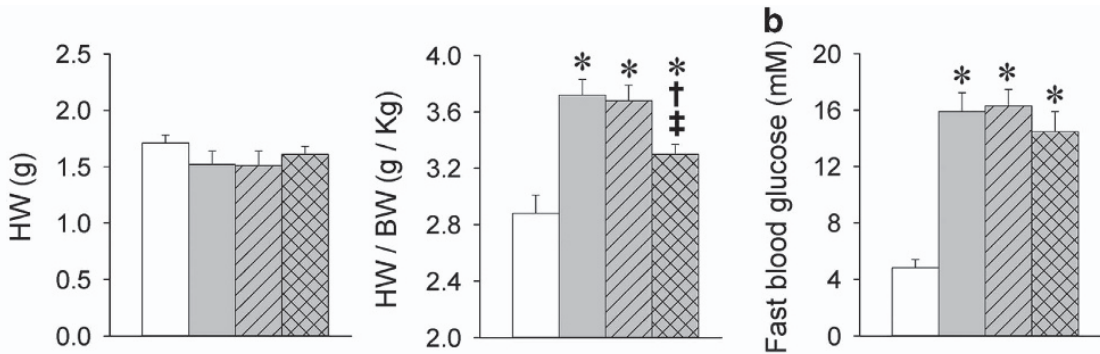

d
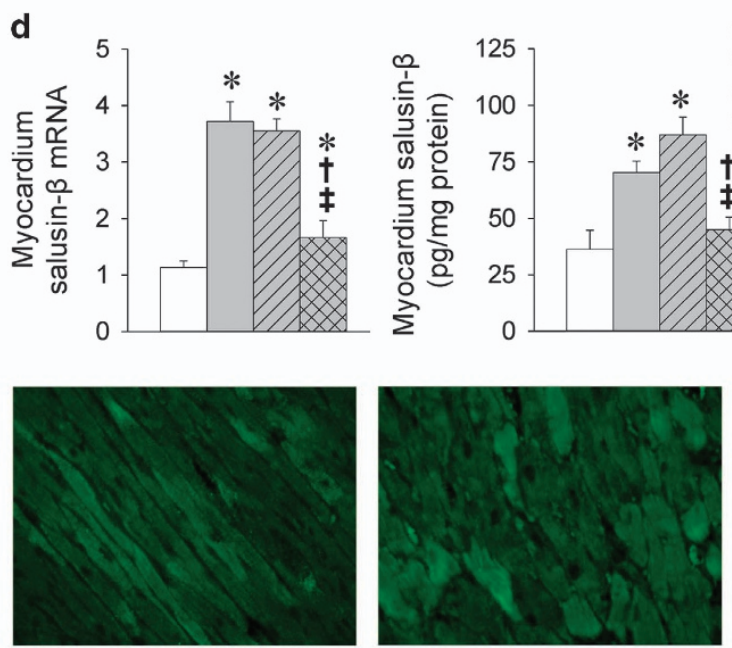

Ctrl

एDM

DM/Ad-Scr-shRNA

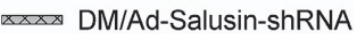

I
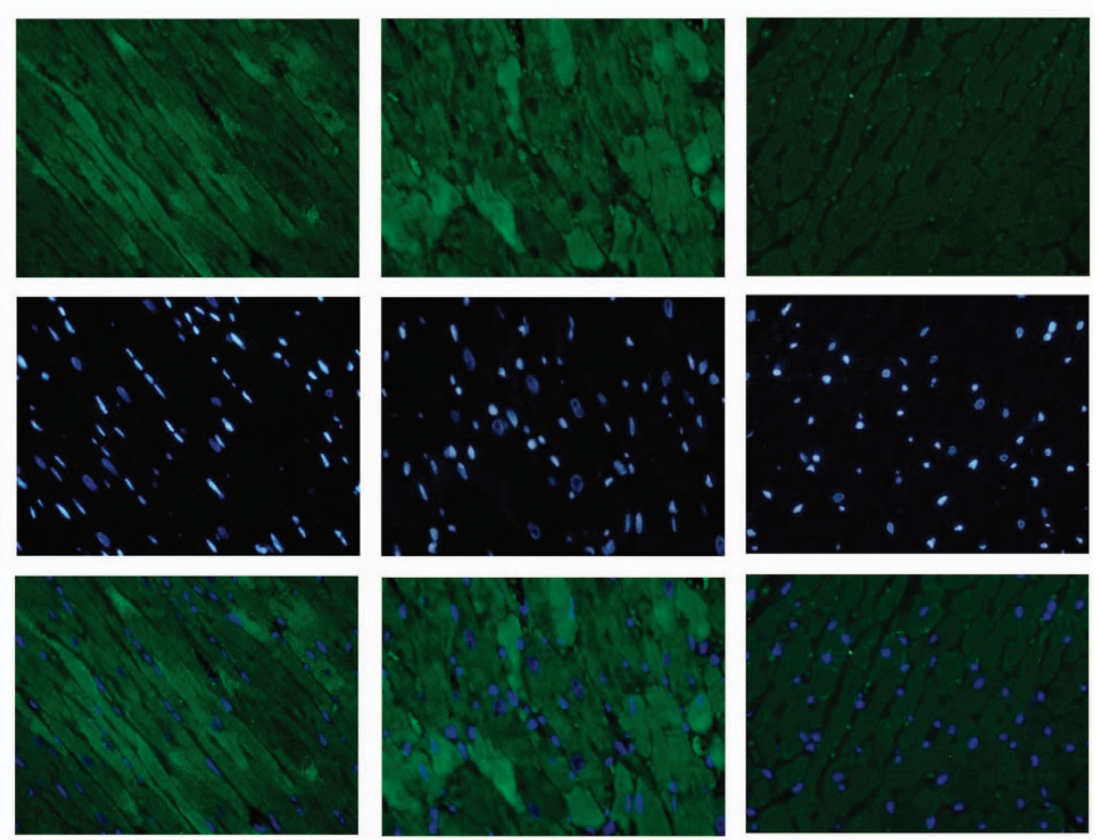

DM

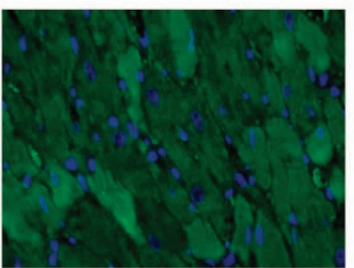

DM/Ad-Scr-shRNA

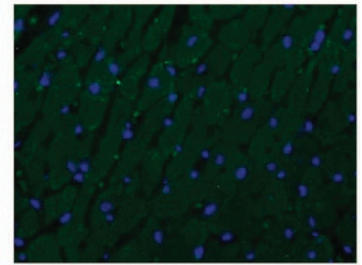

DM/Ad-Salusin-shRNA

Figure 5 Effects of interrupting salusin- $\beta$ on body weight (BW), heart weight (HW), fast blood glucose and salusin- $\beta$ expression levels in rats with diabetes (DM). Intravenous injection of adenoviral vectors encoding salusin- $\beta$ shRNA (Ad-Salusin-shRNA, $2.0 \times 10^{10}$ plaque-forming units) or scramble shRNA (Ad-Scr-shRNA) were carried out and repeated for 2 weeks in rats. The measurements were made 4 weeks after the first adenovirus transfer. (a) BW, HW and HW/BW. (b) Fast blood glucose. (c) Plasma salusin- $\beta$ levels. (d) Salusin- $\beta$ mRNA and protein expression in myocardium. (e) Immunofluorescence staining for salusin- $\beta$ in myocardium. Values are mean \pm S.E.M. ${ }^{*} P<0.05$ versuS Ctrl; ${ }^{\dagger} P<0.05$ versus $\mathrm{DM} ;{ }^{\ddagger} P<0.05$ versus DM/Ad-Scr-shRNA. $n=6$

Salusin- $\beta$ knockdown improves ventricle functions in diabetic rats. Ratio of heart weight to body weight was increased in rats with diabetes mellitus (DM), which was attenuated by Ad-Salusin-shRNA (Figure 5a). Echocardiographic assessment showed that left ventricular internal dimensions (LVIDs), left ventricular mass (LVM)/BW were increased, whereas ejection fraction (EF) and fractional shortening (FS) were reduced in diabetic rats, which were attenuated by Ad-Salusin-shRNA (Table 1). These results indicate that knockdown of salusin- $\beta$ improves cardiomyopathy in type 2 diabetes.
Salusin- $\beta$ knockdown fails to attenuate hyperglycemia and insulin resistance in diabetic rats. Diabetic rats showed much higher fast blood glucose level than that in control rats, which was not affected by Ad-Salusin-shRNA (Figure 5b). Insulin tolerance test (ITT) was used for evaluating insulin resistance, and the efficiency of insulin was quantified by its ability in reducing blood glucose level. Insulin was less effective in DM rats than that in control rats, suggesting impaired insulin sensitivity in diabetic rats. AdSalusin-shRNA had no significant role in improving the insulin sensitivity in diabetic rats. Glucose tolerance test (GTT) was 
Table 1 Echocardiographic assessment of left ventricle dimensions and functions in rats

\begin{tabular}{|c|c|c|c|c|}
\hline & Ctrl & DM & DM Scr-shRNA & DM Salusin- $\beta$-shRNA \\
\hline LVIDs (mm) & $4.66 \pm 0.20$ & $5.71 \pm 0.18^{*}$ & $5.69 \pm 0.20^{*}$ & $5.14 \pm 0.17^{\star \dagger \ddagger}$ \\
\hline LVIDd (mm) & $8.36 \pm 0.30$ & $8.60 \pm 0.22$ & $8.35 \pm 0.27$ & $8.52 \pm 0.18$ \\
\hline IVSs (mm) & $3.25 \pm 0.16$ & $2.56 \pm 0.19^{\star}$ & $2.51 \pm 0.18^{*}$ & $2.53 \pm 0.14^{*}$ \\
\hline IVSd (mm) & $1.91 \pm 0.14$ & $1.70 \pm 0.13$ & $1.75 \pm 0.15$ & $1.73 \pm 0.13$ \\
\hline LVPWs (mm) & $3.20 \pm 0.15$ & $2.57 \pm 0.09^{*}$ & $2.49 \pm 0.13^{*}$ & $2.79 \pm 0.14^{*}$ \\
\hline LVPWd (mm) & $1.96 \pm 0.06$ & $1.74 \pm 0.08^{*}$ & $1.76 \pm 0.05^{*}$ & $1.83 \pm 0.07$ \\
\hline LVVs $(\mu \mathrm{l})$ & $103 \pm 11$ & $165 \pm 13^{*}$ & $157 \pm 11^{*}$ & $137 \pm 9^{*}$ \\
\hline $\operatorname{LVVd}(\mu \mathrm{l})$ & $383 \pm 16$ & $392 \pm 21$ & $387 \pm 18$ & $398 \pm 18$ \\
\hline $\operatorname{LVM}(\mathrm{g})$ & $1.11 \pm 0.10$ & $0.95 \pm 0.11$ & $0.92 \pm 0.08$ & $0.91 \pm 0.07$ \\
\hline LVM/BW (g/kg) & $1.85 \pm 0.13$ & $2.30 \pm 0.16^{*}$ & $2.26 \pm 0.11^{*}$ & $1.88 \pm 0.10^{\dagger \ddagger}$ \\
\hline $\mathrm{EF}(\%)$ & $73.1 \pm 2.6$ & $57.9 \pm 2.2^{*}$ & $58.1 \pm 2.2^{*}$ & $65.6 \pm 1.7^{\star \dagger \ddagger}$ \\
\hline FS (\%) & $44.0 \pm 1.3$ & $33.6 \pm 1.8^{*}$ & $32.9 \pm 1.5^{\star}$ & $38.5 \pm 1.8^{\star \dagger \neq}$ \\
\hline
\end{tabular}

Abbreviations: BW, body weight; EF, ejection fraction; FS, fractional shorting; IVSs and IVSd, interventricular septum at end systole and diastole; LVIDs and LVIDd, left ventricular internal dimensions at end systole and diastole; LVPWs and LVPWd, left ventricular posterior wall dimensions at end systole and diastole; LVVs and LVVd, left ventricular volume at end systole and diastole; LVM, left ventricular mass

Values are mean \pm S.E.M. ${ }^{\star} P<0.05$ versus Ctrl; ${ }^{\dagger} P<0.05$ versus $\mathrm{DM} ;{ }^{\ddagger} P<0.05$ versus DM/Scr-shRNA. $n=6$

used for evaluating glucose tolerance. Diabetic rats manifested significantly elevated glucose excursions following glucose challenge compared with control rats. Ad-SalusinshRNA had no significant effect on the glucose excursion (Supplementary Figure 4).

Salusin- $\beta$ expression levels in diabetic rats. Plasma salusin- $\beta$ levels were increased in diabetic rats. Salusin- $\beta$ mRNA and protein expression levels in myocardium were unregulated in diabetic rats. Furthermore, immunofluorescence staining showed the enhanced salusin- $\beta$ immunofluorescence in myocardium of diabetic rats. Ad-Salusin-shRNA significantly reduced plasma salusin- $\beta$ levels and salusin- $\beta$ expression in myocardium of diabetic rats (Figures $5 c-e$ ).

Salusin- $\beta$ knockdown attenuates inflammation in diabetic rats. IL- $1 \beta$, IL- 6 , TNF- $\alpha$ and VCAM-1 mRNA levels were increased in diabetic rats, which were prevented by salusin- $\beta$ knockdown with Ad-Salusin-shRNA (Figure 6a). Similarly, IL- $1 \beta$, IL-6, TNF- $\alpha$ and VCAM-1 proteins were upregulated in diabetic rats, which were attenuated by Ad-Salusin-shRNA (Figure 6b).

Salusin- $\beta$ knockdown reduces NF $\kappa$ B activation, NOX2 expression and ROS production in diabetic rats. Diabetic rats showed increased p65 in nucleus and reduced p65 in cytoplasm, which were prevented by Ad-Salusin-shRNA (Figure 7a). NOX2 and NOX4 expression levels, as well as 4-HNE levels, were increased in myocardium of diabetic rats. Ad-Salusin-shRNA reduced NOX2 expression levels and 4-HNE levels, but not NOX4 expression in diabetic rats (Figure 7b). Dihydroethidium (DHE) fluorescent dye further confirmed that increased ROS production in diabetic myocardium were attenuated by Ad-Salusin-shRNA (Figure 7c).

\section{Discussion}

Sustained increased inflammatory cytokines in myocardium are involved in augmenting remodeling process. ${ }^{25}$ The levels of inflammatory cytokines in myocardium were increased in diabetic animal models. ${ }^{26}$ Accumulating evidences suggest increased oxidative stress coupled with activation of downstream pro-inflammatory cytokines have pivotal roles in the development of DCM. ${ }^{26-29}$ It has been found that plasma salusin- $\beta$ levels were increased in patients with diabetes. ${ }^{17}$ ROS production was involved in the effects of salusin- $\beta$ in brain ${ }^{10}$ and VSMCs. ${ }^{14}$ The primary novel findings in this study are that salusin- $\beta$ contributes to oxidative stress and inflammation in DCM via NFKB signaling, and that knockdown of salusin- $\beta$ attenuates cardiac dysfunction, oxidative stress and inflammation in DCM.

Cardiomyocytes cultured in HG was used as a model to mimic the increased glucose level in diabetes. ${ }^{30} \mathrm{HG}$ increased salusin- $\beta$ mRNA levels and upregulated salusin- $\beta$ and its precursor prosalusin protein expression levels in $\mathrm{H} 9 \mathrm{c} 2$ cells, suggesting that $\mathrm{HG}$ is a stimulator of salusin- $\beta$ expression at both transcriptional and post-translational levels. Either HG or salusin- $\beta$ alone caused inflammation, NOX2 upregulation and oxidative stress in $\mathrm{H} 9 \mathrm{c} 2$ cells, which were further confirmed in neonatal rat cardiomyocytes. HG or salusin- $\beta$ increased NOX2 mRNA levels, suggesting transcriptional regulation is involved in the HG- or salusin- $\beta$-induced NOX2 upregulation. As diabetic patients showed an increase in plasma salusin- $\beta$ levels, ${ }^{17}$ the effects of combined salusin- $\beta$ and HG were examined in vitro to mimic the upregulated salusin- $\beta$ and hyperglycemia situations of diabetes. Salusin- $\beta$ induced more potent inflammation, NOX2 upregulation and oxidative stress responses in $\mathrm{HG}$-treated $\mathrm{H} 9 \mathrm{c} 2$ cells than those in control cells. Knockdown of salusin- $\beta$ with shRNA in neonatal rat cardiomyocytes attenuated HG-induced inflammation and NOX2 upregulation and oxidative stress. Inhibiting NOX with DPI or scavenging ROS with NAC attenuated inflammation in both control and $\mathrm{HG}$-treated $\mathrm{H} 9 \mathrm{c} 2$ cells. These results indicate that salusin- $\beta$ is a stimulator of inflammation and oxidative stress in cardiomyocytes, and salusin- $\beta$ is at least partially responsible for HG-induced inflammation mediated by NOX2-derived ROS production.

$\mathrm{NF} K \mathrm{~B}$ is a transcription factor that is activated by various stimuli such as cytokines, ROS, bacterial or viral products. Activated NF $\mathrm{NB}_{\mathrm{B}}$ translocates into the nucleus and stimulates related gene expression. ${ }^{31}$ As a key transcription factor related to inflammation, $\mathrm{NF}_{K} \mathrm{~B}$ has been shown to have a pivotal role in 

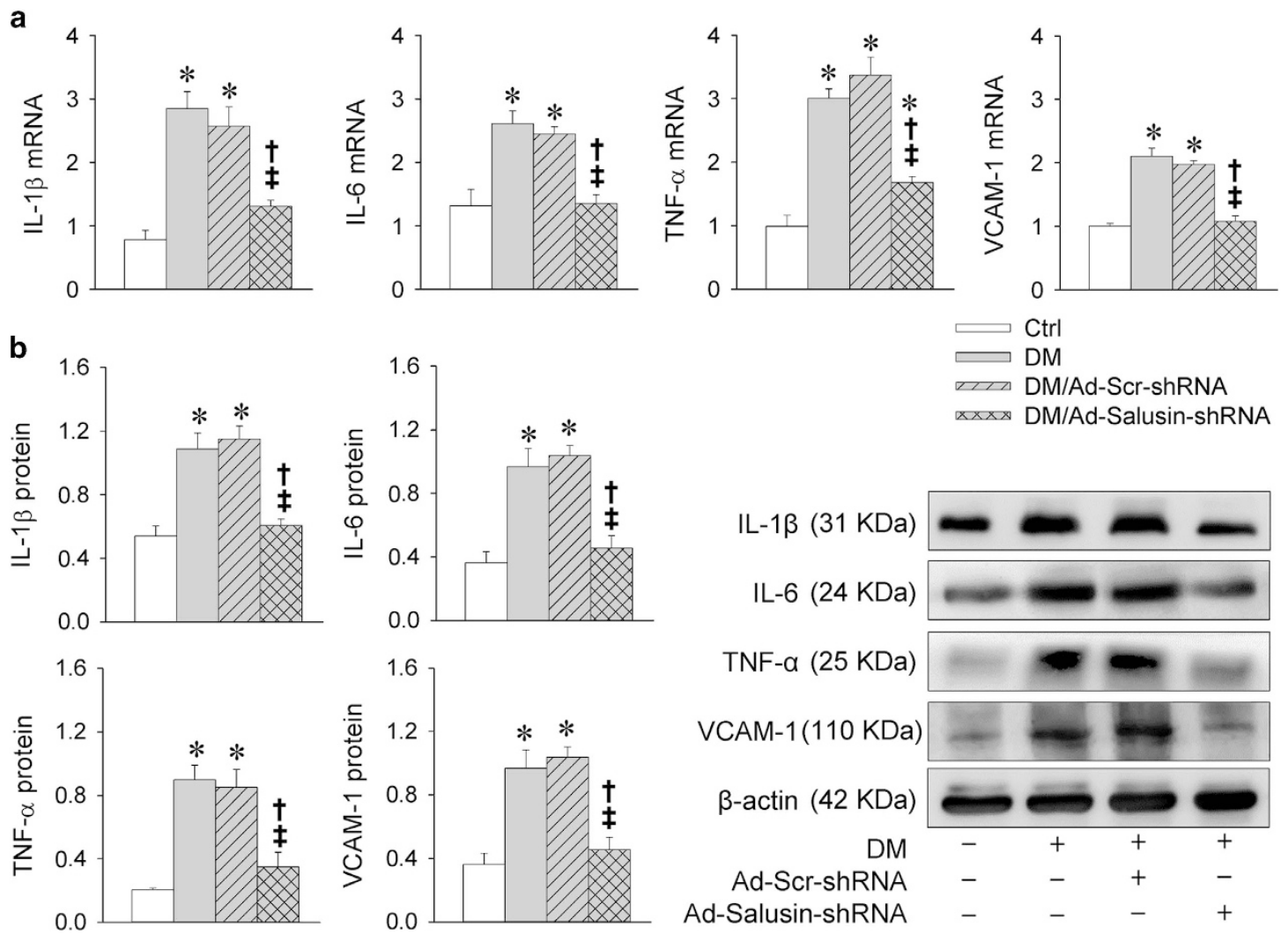

Figure 6 Effects of interrupting salusin- $\beta$ on inflammation in myocardium in rats with diabetes (DM). Intravenous injection of adenoviral vectors encoding salusin- $\beta$ shRNA (Ad-Salusin-shRNA, $2.0 \times 10^{10}$ plaque-forming units) or scramble shRNA (Ad-Scr-shRNA) were carried out and repeated for 2 weeks in rats. The measurements were made 4 weeks after the first adenovirus transfer. (a) Relative mRNA levels of IL-1 $\beta$, IL-6, TNF- $\alpha$ and VCAM-1. (b) Relative protein expression levels of IL-1 $\beta$, IL-6, TNF- $\alpha$ and VCAM-1. Values are mean \pm S.E.M. ${ }^{*} P<0.05$ versus $C$ trl; ${ }^{\dagger} P<0.05$ versus $\mathrm{DM} ;{ }^{\ddagger} P<0.05$ versus DM/Ad-Scr-shRNA. $n=6$

the development of $\mathrm{DCM}{ }^{32} \mathrm{NF} \kappa \mathrm{B}$ activation has been found in primary human cardiomyocytes exposed to $\mathrm{HG}^{26}$ In this study, HG-induced NFKB activation in both $\mathrm{H} 9 \mathrm{c} 2$ and neonatal rat cardiomyocytes. Salusin- $\beta$ caused greater NF $K B$ activation response in HG-treated $\mathrm{H} 9 \mathrm{c} 2$ cells than those in control cells. Knockdown of salusin- $\beta$ with shRNA in neonatal rat cardiomyocytes inhibited $\mathrm{HG}$-induced $\mathrm{NF} \kappa \mathrm{B}$ activation. Inhibiting NOX with DPI or scavenging ROS with NAC attenuated salusin- $\beta$-induced $\mathrm{NF} \kappa \mathrm{B}$ activation in both control and HGtreated $\mathrm{H} 9 \mathrm{c} 2$ cells. Inhibition of NF $\kappa$ B with Bay 11-7082 had no significant effects on salusin- $\beta$-induced NOX upregulation and ROS production, but attenuated salusin- $\beta$-induced inflammation in both control and HG-treated H9c2 cells. These results indicate that NFKB pathway mediates HG- or salusin- $\beta$ induced inflammation via NOX2-derived ROS production in cardiomyocytes.

Low-dose streptozotocin (STZ) combined with high-fat diet (HFD)-induced diabetes in rodents has been identified as an ideal animal model of type 2 diabetes, which simulates the metabolic characteristics and disease progression of type 2 diabetes. ${ }^{33,34}$ This model is appropriate for testing antidiabetic agents in treatment of type 2 diabetes..$^{35}$ In this study, combined treatment with STZ and HFD caused increases in fasting blood glucose, insulin resistance and ratio of heart weight to body weight, and decreases in glucose tolerance and ventricular function in rats. These results confirm that the type 2 diabetes with cardiomyopathy rat model was successfully established, which is consistently with previous studies. $^{36-38}$ NOX2 upregulation, oxidative stress, NFKB activation and inflammation were found in the myocardium of DM rats, which were attenuated by silencing salusin- $\beta$ gene in diabetic rats. Furthermore, plasma salusin- $\beta$ levels and myocardium salusin- $\beta$ expression levels in myocardium were increased in diabetic rats. More importantly, silencing salusin$\beta$ gene improved ventricular dysfunction in DM. These results indicate the important role of salusin- $\beta$ in the pathogenesis of $D C M$, and further support the findings that $H G$ stimulates salusin- $\beta$ expression, which causes oxidative stress followed by $N F K B$ activation and inflammation. Salusin $\beta$ may be taken as a target in attenuating cardiomyopathy in DM.

Insulin had no significant effects on the baseline salusin- $\beta$ and NOX2 expression levels or on the HG-induced upregulation of salusin- $\beta$ and NOX2 in H9c2 cells, suggest that insulin is not involved in the HG-induced salusin- $\beta$ and NOX2 expression levels in vitro. Knockdown of salusin- $\beta$ had no significant effects in attenuating hyperglycemia and insulin resistance in DM rats, which suggests that salusin- $\beta$ is not involved in the pathogenesis of hyperglycemia and insulin resistance in diabetes. The beneficial roles of knockdown of salusin- $\beta$ in attenuating oxidative stress and inflammation in diabetes are independently of blood glucose and insulin resistance in DM rats. 

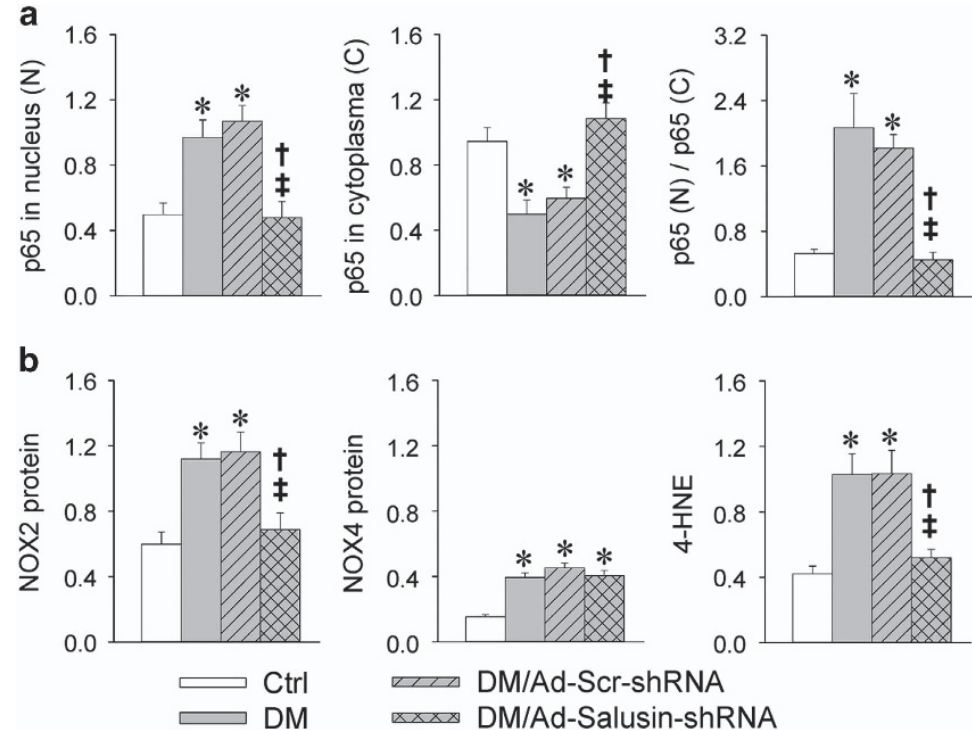

Ctrl
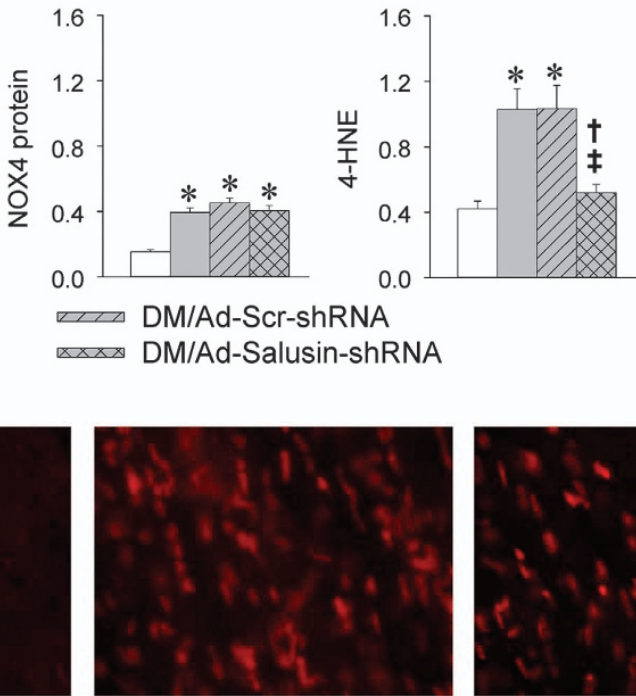

DM

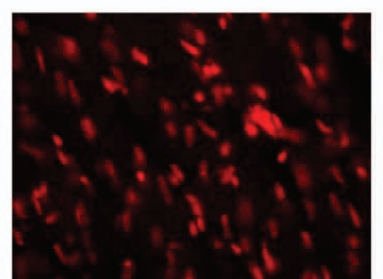

Ad-DM/Scr-shRNA
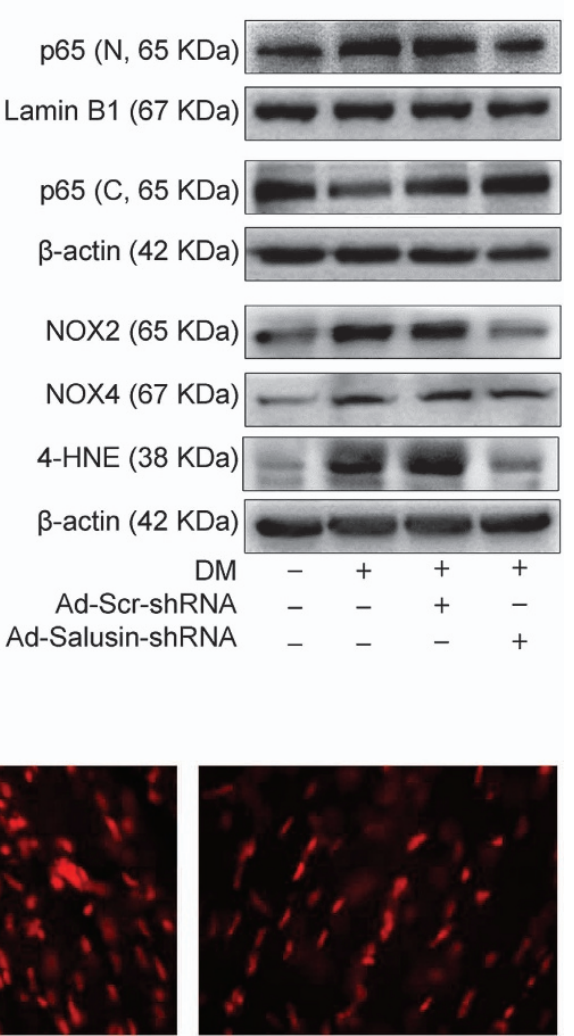

DM/Ad-Salusin-shRNA

Figure 7 Effects of interrupting salusin- $\beta$ on $\mathrm{NF}_{\kappa} \mathrm{B}$ activation and oxidative stress in myocardium in rats with diabetes (DM). Intravenous injection of adenoviral vectors encoding salusin- $\beta$ shRNA (Ad-Salusin-shRNA, $2.0 \times 10^{10}$ plaque-forming units) or scramble shRNA (Ad-Scr-shRNA) were carried out and repeated for 2 weeks in rats. The measurements were made 4 weeks after the first adenovirus transfer. (a) NF $k$ B activation. (b) Oxidative stress. (c) DHE staining for detecting ROS in myocardium. Values are mean \pm S.E.M. ${ }^{*} P<0.05$ versus $C$ trl; ${ }^{\dagger} P<0.05$ versus DM; ${ }^{\ddagger} P<0.05$ versus DM/Ad-Scr-shRNA. $n=6$

In conclusion, salusin- $\beta$ promotes cardiac inflammation via NOX2-derived ROS production and nucleus translocation of p65-NFKB. Knockdown of salusin- $\beta$ attenuates cardiac dysfunction, oxidative stress and inflammation in DCM. Our findings provided a new insight toward the development of therapeutic agents aimed at reducing cardiac inflammation and oxidative stress in DCM.

\section{Materials and Methods}

All experiments adhered to the Care and Use of Laboratory Animal published by the US National Institutes of Health (NIH publication, 8th edition, 2011) and approved by the Experimental Animal Care and Use Committee of Nanjing Medical University.

Cell culture of H9c2 cells and neonatal rat cardiomyocytes. H9c2 rat cardiomyoblast cells were obtained from Costar Corning Inc. (Corning, CA, USA). Neonatal rat cardiomyocytes were isolated enzymatically from 1 to 3 days old SD rats (Animal Center of Nanjing Medical University, Nanjing, China). Briefly, left ventricles were minced and digested with $0.04 \%$ collagenase II (Sigma, St. Louis, MO, USA). The supernatant-containing suspended cells were preplated for $1.5 \mathrm{~h}$ to remove non-myocytes. Then, the cardiomyocytes were seeded onto culture plates at about $5 \times 10^{4} \mathrm{cell} / \mathrm{s} / \mathrm{cm}^{2}$, and cultured in the medium containing DMEM/F-12 with HEPES (Hyclone, Beijing, China), 10\% FBS (Gibco, Grand Island, NY, USA), 1\% penicillin and $1 \%$ streptomycin (Solarbio, Beijing, China) with $5 \% \mathrm{CO}_{2}$ at $37^{\circ} \mathrm{C}$ Cardiomyocytes were seeded for 3 days before use. In order to mimic the increased glucose level in diabetes, the $\mathrm{H} 9 \mathrm{c} 2$ cells or primary neonatal cardiomyocytes were cultured in $33.3 \mathrm{mM}$ glucose $(\mathrm{HG})$ or $5.5 \mathrm{mM}$ glucose (normal glucose), the latter of which was used as a control for indicated time. ${ }^{30}$

Rat model of type 2 diabetes and knockdown of salusin- $\beta$. Combination of low-dose STZ and HFD were used to induce type 2 diabetes. ${ }^{33-35}$ Control diet (20\% protein, $3 \%$ fat, $3 \%$ fiber and 74\% carbohydrate) and HFD (34.5\% fat, $17.5 \%$ protein and $48 \%$ carbohydrate) were obtained from Beijing HFK Bio-Technology Co. Ltd (Beijing, China). Male SD rats weighing 120-140 g were used in the experiments, which were housed in a temperature-controlled room with 12-h light-dark cycles, and had free access to standard chow and tap water. After 2 weeks of acclimatization, rats were randomized divided into four groups. One group of rats (Ctrl group) received an intraperitoneal injection of vehicle or PBS, and were fed with control diet throughout the experiment. Another three groups of rats combined into one group to induce type 2 diabetes. These rats were fed with HFD instead of previously used control diet during the following experiments. After 4 weeks HFD feeding, the diabetic rats were subjected to 12-h fasting followed by intraperitoneal injection of low-dose of STZ $(27.5 \mathrm{mg} / \mathrm{kg}$ body weight, dissolved in $0.1 \mathrm{M}$ citrate buffer, $\mathrm{pH} 4.5)^{36,38}$ Twelve weeks after injection of STZ ( 16 weeks HFD), diabetes was confirmed by the fast blood glucose $>11.1 \mathrm{mmol} / .^{30,38}$ The diabetic rats were re-divided into three groups, which respectively received intravenous injection of PBS (DM group), adenoviral vectors encoding scramble shRNA $\left(2.0 \times 10^{10}\right.$ plaque-forming units, DM/Ad-Scr-shRNA group) or adenoviral vectors encoding salusin- $\beta$ shRNA $\left(2.0 \times 10^{10}\right.$ plaque-forming units, DM/Ad-Salusin-shRNA group). The intravenous injections were repeated 2 weeks after the first administration. ${ }^{14,38}$ The rats were killed for measurements 4 weeks after the first time of intravenous injection (20 weeks after feeding with HFD). Ad-Salusin-shRNA and AdScr-shRNA were constructed by Genomeditech Co. (Shanghai, China), which downregulated the salusin- $\beta$ expression by $75 \%$. The efficiency of Ad-Sal-shRNA in knockdown of salusin- $\beta$ was confirmed in rats in our previous study. ${ }^{14}$ The sequences of 
salusin- $\beta$-shRNA are listed in a table (Supplementary Table 1). The experimental protocols were summarized in a schematic diagram (Supplementary Figure 5).

ITT and GTT. Rats were fasted for $4 \mathrm{~h}$ before intraperitoneal injection of insulin (1 units/kg body weight) for ITT, and fasted for $12 \mathrm{~h}$ before glucose $(1 \mathrm{~g} / \mathrm{kg}$ body weight) for GTT. Blood glucose in tail veins were measured with a blood glucometer (One Touch, Milpitas, CA, USA) at 0, 15, 30, 60 and 120 min after the injection. ${ }^{38}$

Echocardiography. Cardiac function was measured with Vevo2100 imaging system (VisualSonics, Toronto, Canada). All measurements were the average of six consecutive cardiac cycles and performed by the same operator. The derived echocardiography parameters included LVID, interventricular septum thickness, left ventricular posterior wall dimension, left ventricular volume, LVM, EF and FS.

ELISA. Commercial ELISA kits (Uscn Life Science, Houston, TX, USA) were used for the measurement of salusin- $\beta, \mathrm{IL}-1 \beta, \mathrm{IL}-6$ and TNF- $\alpha$ in according to the manufacturer's instructions. Briefly, the samples were collected and added into the pre-coated ELISA plate $\left(100 \mu \mathrm{l}\right.$ per well). Plates were incubated at $37^{\circ} \mathrm{C}$ for $2 \mathrm{~h}$, washed and then incubated with conjugated solution for $1 \mathrm{~h}$ at $37^{\circ} \mathrm{C}$. Finally, the reactions were stopped with stop solution, and optical density was determined by use of a microplate reader (ELX800, BioTek, Winoosk, VT, USA) at $450 \mathrm{~nm}$.

Western blot analysis. Prosalusin, VCMA-1, NOX2, NOX4, 4-HNE, p65, IL-1 $\beta$, IL-6 and TNF- $\alpha$ were determined with western blot analysis. Briefly, tissues or cardiomyocytes were sonicated in RIPA lysis buffer and homogenized. The debris was removed, and the supernatant was obtained by centrifugation at $4{ }^{\circ} \mathrm{C}$. Total or nuclear proteins were extracted using commercially available kits (Beyotime Biotechnology, Shanghai, China) according to the manufacturer's protocol. Equal amounts of protein were separated on sodium dodecyl sulfate-polyacrylamide gel electrophoresis and transferred onto PVDF membrane. Blocking was made at room temperature with $5 \%$ nonfat milk powder prepared in Tris-buffered saline containing $0.1 \%$ Tween 20. Then, membranes were incubated overnight at $4{ }^{\circ} \mathrm{C}$ with the primary antibodies followed by incubation with appropriate HRP-linked secondary antibody. The protein expression levels were visualized by enhanced chemiluminescence (Millipore, Billerica, MA, USA). Primary antibodies of IL-6, TNF- $\alpha$, NOX2, NOX4, 4-HNE and secondary antibodies were purchased from Abcam (Cambridge, MA, USA). Antibodies of VCMA-1, IL-1 $\beta$, p65 and $\beta$-actin were obtained from Biotechnology Inc. (Dallas, TX, USA). Antibodies of lamin B1 was purchased from Santa Cruz Biotechnology Co. (Santa Cruz, CA, USA). Antibodies of prosalusin was obtained from Proteintech Group Inc. (Rosemont, IL, USA).

RT-PCR. Salusin- $\beta$, NOX2, IL-1 $\beta$, IL-6, TNF- $\alpha$ and VCAM-1 mRNA were analyzed by real-time quantitative PCR. Total RNA was separated using a Trizol reagent (Life Technologies, Gaithersburg, MD, USA) according to the manufacturer's protocols. RNA concentrations and purity were assessed by the measurement of optical density at 260 and $280 \mathrm{~nm}$. Reverse transcriptase reactions were made using the PrimeScript RT reagent Kits (Takara, Otsu, Shiga, Japan) according to the manufacturer's instruction. Real-time PCR was performed with Quantitative PCR with SYBR Premix Ex Taq TM (Takara), and ABI PRISM 7500 sequence detection PCR system (Applied Biosystems, Foster City, CA, USA). The samples were relatively quantified by normalizing the targeted gene level to that of internal control by the $\Delta \Delta \mathrm{Ct}$ method. The sequences of primers were listed in Supplementary Table 2.

DHE fluorescence staining. ROS production in myocardium was evaluated with DHE staining. Left ventricles were excised from rats, and immediately embedded in OCT compound. The tissues were cut into $25 \mu \mathrm{m}$ thick sections, and then were incubated with DHE $(10 \mu \mathrm{mol} / /)$ in PBS in a dark and humidified container at $37^{\circ} \mathrm{C}$ for $5 \mathrm{~min}$. DHE is oxidized upon reaction with superoxide to ethidium bromide, which binds to DNA in the nucleus. The fluorescence were viewed under the fluorescence microscope (DP70, Olympus Optical, Tokyo, Japan).

Salusin- $\boldsymbol{\beta}$ immunofluorescence. Paraffin-embedded sections were permeabilized using $0.1 \%$ Triton $\mathrm{X}-100$ for $10 \mathrm{~min}$ after deparaffinization and rehydration. The sections were washed in PBS then blocked with $10 \%$ goat serum for $1 \mathrm{~h}$, and then incubated with rabbit anti-salusin- $\beta$ antibody overnight at $4{ }^{\circ} \mathrm{C}$. The secondary TRITC-conjugated goat anti-rabbit IgG $(1: 400)$ was used. Nuclei were stained with 4',6-diamidino-2-phenylindole after immunofluorescence staining. The fluorescence signal was obtained using a fluorescence microscope (DX51, Olympus, Tokyo, Japan).

Statistical analysis. Comparisons between two groups were made by Student's $t$-test. One-way or two-way ANOVA followed by post hoc Bonferroni test was used when multiple comparisons were made. All data were expressed as mean \pm S.E.M. A value of $P<0.05$ was considered statistically significant.

\section{Conflict of Interest}

The authors declare no conflict of interest.

Acknowledgements. This work was supported by National Natural Science Foundation of China (31571167, 91639105, 31171095 and 91439120). The authors gratefully acknowledge the generous support of the Collaborative Innovation Center for Cardiovascular Disease Translational Medicine.

1. Aneja A, Tang WH, Bansilal S, Garcia MJ, Farkouh ME. Diabetic cardiomyopathy: insights into pathogenesis, diagnostic challenges, and therapeutic options. Am J Med 2008; 121: 748-757.

2. Li X, Du N, Zhang Q, Li J, Chen X, Liu X et al. MicroRNA-30d regulates cardiomyocyte pyroptosis by directly targeting foxo3a in diabetic cardiomyopathy. Cell Death Dis 2014; 5 : e1479.

3. Miki T, Yuda S, Kouzu H, Miura T. Diabetic cardiomyopathy: pathophysiology and clinical features. Heart Fail Rev 2013; 18: 149-166.

4. Folli F, Corradi D, Fanti P, Davalli A, Paez A, Giaccari A et al. The role of oxidative stress in the pathogenesis of type 2 diabetes mellitus micro- and macrovascular complications: avenues for a mechanistic-based therapeutic approach. Curr Diabetes Rev 2011; 7: 313-324.

5. Kayama Y, Raaz U, Jagger A, Adam M, Schellinger IN, Sakamoto M et al. Diabetic cardiovascular disease induced by oxidative stress. Int J Mol Sci 2015; 16: 25234-25263.

6. Boudina S, Abel ED. Diabetic cardiomyopathy, causes and effects. Rev Endocr Metab Disord 2010; 11: 31-39.

7. Shichiri M, Ishimaru S, Ota T, Nishikawa T, Isogai T, Hirata Y. Salusins: newly identified bioactive peptides with hemodynamic and mitogenic activities. Nat Med 2003; 9: 1166-1172.

8. Suzuki N, Shichiri M, Akashi T, Sato K, Sakurada M, Hirono Y et al. Systemic distribution of salusin expression in the rat. Hypertens Res 2007; 30: 1255-1262.

9. Sun HJ, Zhou H, Feng XM, Gao Q, Ding L, Tang CS et al. Superoxide anions in the paraventricular nucleus mediate cardiac sympathetic afferent reflex in insulin resistance rats. Acta Physiol (Oxf) 2014; 212: 267-282.

10. Sun HJ, Zhang LL, Fan ZD, Chen D, Zhang L, Gao XY et al. Superoxide anions involved in sympathoexcitation and pressor effects of salusin-beta in paraventricular nucleus in hypertensive rats. Acta Physiol (Oxf) 2014; 210: 534-545.

11. Zhang LL, Ding L, Zhang F, Gao R, Chen Q, Li YH et al. Salusin-beta in rostral ventrolateral medulla increases sympathetic outflow and blood pressure via superoxide anions in hypertensive rats. J Hypertens 2014; 32: 1059-1067.

12. Sun HJ, Liu TY, Zhang F, Xiong XQ, Wang JJ, Chen $Q$ et al. Salusin-beta contributes to vascular remodeling associated with hypertension via promoting vascular smooth muscle cell proliferation and vascular fibrosis. Biochim Biophys Acta 2015; 1852: 1709-1718.

13. Sun HJ, Zhao MX, Liu TY, Ren XS, Chen Q, Li YH et al. Salusin-beta induces foam cell formation and monocyte adhesion in human vascular smooth muscle cells via miR155/ NOX2/NFkappaB pathway. Sci Rep 2016; 6: 23596

14. Sun HJ, Zhao MX, Ren XS, Liu TY, Chen Q, Li YH et al. Salusin-beta promotes vascular smooth muscle cell migration and intimal hyperplasia after vascular injury via ROS/ NFkappaB/MMP-9 pathway. Antioxid Redox Signal 2016; 24: 1045-1057.

15. Koya T, Miyazaki T, Watanabe T, Shichiri M, Atsumi T, Kim-Kaneyama JR et al. Salusin- $\beta$ accelerates inflammatory responses in vascular endothelial cells via NF-kappaB signaling in LDL receptor-deficient mice in vivo and HUVECs in vitro. Am J Physiol Heart Circ Physiol 2012: 303: H96-105.

16. Zhou CH, Pan J, Huang H, Zhu Y, Zhang M, Liu L et al. Salusin-beta, but not salusin-alpha, promotes human umbilical vein endothelial cell inflammation via the p38 MAPK/JNK-NFkappaB pathway. PLOS ONE 2014; 9: e107555.

17. Fujimoto K, Hayashi A, Kamata $Y$, Ogawa A, Watanabe T, Ichikawa R et al. Circulating levels of human salusin-beta, a potent hemodynamic and atherogenesis regulator. PLOS ONE 2013; 8: e76714.

18. Aydin S, Aydin S. Salusin-alpha and -beta expression in heart and aorta with and without metabolic syndrome. Biotech Histochem 2014; 89: 98-103.

19. Nagashima A, Nakajima T, Ogawa M, Suzuki J, Shichiri M, Isobe M. A critical role of salusinbeta in myocardial ischemia. J Card Fail 2009; 15: S172.

20. Lin CC, Pan CS, Wang CY, Liu SW, Hsiao LD, Yang CM. Tumor necrosis factor-alpha induces VCAM-1-mediated inflammation via c-Src-dependent transactivation of EGF receptors in human cardiac fibroblasts. J Biomed Sci 2015; 22: 53. 
21. Yamaguchi T, Yoneyama M, Hinoi E, Ogita K. Involvement of calpain in 4-hydroxynonenalinduced disruption of gap junction-mediated intercellular communication among fibrocytes in primary cultures derived from the cochlear spiral ligament. J Pharmacol Sci 2015; 129: 127-134.

22. Suzuki H, Kayama Y, Sakamoto M, luchi H, Shimizu I, Yoshino T et al. Arachidonate 12/15-lipoxygenase-induced inflammation and oxidative stress are involved in the development of diabetic cardiomyopathy. Diabetes 2015; 64: 618-630.

23. Garufi A, Trisciuoglio D, Cirone M, D'Orazi G. ZnCl2 sustains the adriamycin-induced cell death inhibited by high glucose. Cell Death Dis 2016; 7: e2280.

24. Bagnati M, Ogunkolade BW, Marshall C, Tucci C, Hanna K, Jones TA et al. Glucolipotoxicity initiates pancreatic $\beta$-cell death through TNFR5/CD40-mediated STAT1 and NF- $\kappa B$ activation. Cell Death Dis 2016; 7: e2329.

25. Nian M, Lee P, Khaper N, Liu P. Inflammatory cytokines and postmyocardial infarction remodeling. Circ Res 2004; 94: 1543-1553.

26. Rajesh M, Mukhopadhyay P, Batkai S, Patel V, Saito K, Matsumoto S et al. Cannabidiol attenuates cardiac dysfunction, oxidative stress, fibrosis, and inflammatory and cell death signaling pathways in diabetic cardiomyopathy. J Am Coll Cardiol 2010; 56 : 2115-2125.

27. Chen J, Zhang Z, Cai L. Diabetic cardiomyopathy and its prevention by nrf2: current status. Diabetes Metab J 2014; 38: 337-345.

28. Kajstura J, Fiordaliso F, Andreoli AM, Li B, Chimenti S, Medow MS et al. IGF-1 overexpression inhibits the development of diabetic cardiomyopathy and angiotensin II-mediated oxidative stress. Diabetes 2001; 50: 1414-1424.

29. Cai L, Wang Y, Zhou G, Chen T, Song Y, Li X et al. Attenuation by metallothionein of early cardiac cell death via suppression of mitochondrial oxidative stress results in a prevention of diabetic cardiomyopathy. J Am Coll cardiol 2006; 48: 1688-1697.

30. Xia Y, Gong L, Liu H, Luo B, Li B, Li R et al. Inhibition of prolyl hydroxylase 3 ameliorates cardiac dysfunction in diabetic cardiomyopathy. Mol Cell Endocrinol 2015; 403: 21-29.

31. Gilmore TD. Introduction to NF-kappaB: players, pathways, perspectives. Oncogene 2006; 25: 6680-6684.

32. Lorenzo O, Picatoste B, res-Carrasco S, Ramirez E, Egido J, Tunon J. Potential role of nuclear factor kappaB in diabetic cardiomyopathy. Mediators Inflamm 2011; 2011: 652097.
33. Reed MJ, Meszaros K, Entes LJ, Claypool MD, Pinkett JG, Gadbois TM et al. A new rat model of type 2 diabetes: the fat-fed, streptozotocin-treated rat. Metabolism 2000; 49 : 1390-1394.

34. Zhang M, Lv XY, Li J, Xu ZG, Chen L. The characterization of high-fat diet and multiple low-dose streptozotocin induced type 2 diabetes rat model. Exp Diabetes Res 2008; 2008: 704045.

35. Srinivasan K, Viswanad B, Asrat L, Kaul CL, Ramarao P. Combination of high-fat diet-fed and low-dose streptozotocin-treated rat: a model for type 2 diabetes and pharmacological screening. Pharmacol Res 2005; 52: 313-320.

36. Li WB, Zhao J, Liu L, Wang ZH, Han L, Zhong M et al. Silencing of activin receptor-like kinase 7 alleviates aortic stiffness in type 2 diabetic rats. Acta Diabetol 2015; 52: 717-726.

37. Ding WY, Liu L, Wang ZH, Tang MX, Ti Y, Han L et al. FP-receptor gene silencing ameliorates myocardial fibrosis and protects from diabetic cardiomyopathy. J Mol Med (Berl) 2014; 92: 629-640.

38. Ti Y, Xie GL, Wang ZH, Bi XL, Ding WY, Wang J et al. TRB3 gene silencing alleviates diabetic cardiomyopathy in a type 2 diabetic rat model. Diabetes 2011; 60: 2963-2974.

(c) (i) Cell Death and Disease is an open-access journal published by Nature Publishing Group. This work is licensed under a Creative Commons Attribution 4.0 International License. The images or other third party material in this article are included in the article's Creative Commons license, unless indicated otherwise in the credit line; if the material is not included under the Creative Commons license, users will need to obtain permission from the license holder to reproduce the material. To view a copy of this license, visit http://creativecommons.org/licenses/by/4.0/

(C) The Author(s) 2017

Supplementary Information accompanies this paper on Cell Death and Disease website (http://www.nature.com/cddis) 